\title{
DO HIPERLOCAL BAURUENSE PARA O GLOBAL CRIATIVO: AS NOVAS MARCAS DE UMA COMUNICAÇÃO A PARTIR DO EMPODERAMENTO COLABORATIVO
}

\section{FROM BAURU'S HYPERLOCAL TO A GLOBAL CREATIVE: NEW TRACES OF COMMUNICATION BASED ON COLLABORATIVE EMPOWERMENT}

\author{
Angelo Sottovia ARANHA ${ }^{1}$ \\ Giovani Vieira MIRANDA ${ }^{2}$
}

\begin{abstract}
RESUMO: A consolidação das novas tecnologias de comunicação e a possibilidade de se produzir conteúdos noticiosos locais, de forma descentralizada e horizontalizada, podem ser vistas como fatores que impulsionam o desenvolvimento jornalístico em ambientes digitais e possibilitam a valorização do local e o reforço de identidades culturais, que passam a configurar como fontes básicas de significados sociais em contraste com o processo de comunicação habitual dos mass media. A partir desses conceitos, sob as óticas da Economia Criativa e do Jornalismo Hiperlocal, é analisada a experiência de comunicação da Casa do Hip Hop de Bauru, arranjo produtivo criativo local de Bauru, cidade do interior de São Paulo, que tem inovado com a criação de um modelo colaborativo e cidadão frente ao da mídia mainstream da cidade, com novas possibilidades para a seleção, captação, edição e difusão de conteúdos informativos.

Palavras-Chave: Jornalismo Cidadão; Jornalismo Local; Novas Tecnologias.
\end{abstract}

ABSTRACT: The consolidation of new communication technologies and the ability to produce content for local, decentralized and horizontally, can be analyzed as elements that drive the journalistic development in the digital environment enabling the development of local and strengthening of identities that, start to set as a basic source of social meaning in contrast to the usual process of the media. Using these concepts, from the perspective of the Creative Economy and Hyperlocal Journalism, it analyzes the communication experience of the House of Hip Hop Bauru, creative production arrangement place of Bauru, city in the interior of São Paulo, which has innovated with the construction a collaborative model and citizen against the mainstream media of the city with new possibilities for the creation, capture, production and distribution of informative contents.

Keywords: Citizen Journalism; Local Journalism; New technologies.

\footnotetext{
${ }^{1}$ Professor do Curso de Jornalismo da Faculdade de Arquitetura, Artes e Comunicação da Universidade Estadual Paulista Júlio de Mesquita Filho. Doutor em Comunicação e Poéticas Visuais (UNESP), mestre em Projeto Arte e Sociedade (UNESP) e graduado em Comunicação Social/Jornalismo (USP). Email: angelo.sottovia.aranha@gmail.com

${ }^{2}$ Pesquisador do Laboratório de Estudos em Comunicação, Tecnologia e Educação Cidadã (Lecotec) da Unesp. Jornalista e Mestre pelo Programa de Pós-graduação em Comunicação da Faculdade de Arquitetura Artes e Comunicação (FAAC) da Unesp, Campus de Bauru. Email: giovani.vieira.miranda@gmail.com
} 


\section{Comunicação e Novas Tecnologias}

As tecnologias da informação e da comunicação, atreladas à formação de uma economia global têm influenciado as relações humanas ao criar novos processos sociais, econômicos e culturais (CASTELLS, 1996). As mídias se convergem num processo que, segundo Jenkins (2009, p. 29), não deve ser vislumbrado apenas no âmbito tecnológico, mas em meio a "uma transformação cultural, à medida que consumidores são incentivados a [...] fazer conexões em meio a conteúdos midiáticos dispersos". A informação se tornou um bem disputado e de valor crescente - as pessoas querem produzir e compartilhar conhecimento, em uma cultura cada vez mais participativa.

A efetivação das interações mediadas pelo virtual fez com que fossem criadas e ampliadas novas formas de relações sociais e pessoais, com base na proximidade de interesses e identidades, a partir da emergência e consolidação das novas tecnologias de comunicação e informação (PERUZZO, 2003). E a digitalização tem afetado também, intensamente, os espaços dos suportes culturais. A qualidade e a rapidez na transmissão de pacotes de dados em ambientes que permitem a comunicação de forma anônima, e a livre circulação de informações, criaram cenários propícios para a criação e o compartilhamento de conteúdos - por qualquer pessoa; a qualquer tempo e lugar (SILVEIRA, 2010).

As novas tecnologias têm afetado as relações humanas de tal maneira que tais relações já não conseguem mais ser completamente entendidas fora de seu "diálogo" com a tecnologia. Entenda-se, nesta reflexão, o termo 'tecnologia' com o significado apresentado por Castells (1996, p. 5), ao apontar que "a tecnologia não é somente a ciência e as máquinas: é também tecnologia social e organizativa". Em outras palavras, a revolução tecnológica está diretamente relacionada às habilidades de uma sociedade para a difusão e a troca de informações, relacionando-as com o restante do mundo.

A disseminação das tecnologias digitais criou uma nova ambiência para a captação, edição e difusão de conteúdos de interesse público. Esse processo favorece os agentes criativos, que se apropriam dessa tecnologia para a composição de novas narrativas. Ao se apropriarem dessa nova ecologia digital, 
e das Tecnologias da Informação e da Comunicação (TIC's), os grupos vinculados ao jornalismo cidadão produzem conteúdos informativos que rivalizam com as narrativas hegemônicas (ARANHA; XAVIER, 2015, p. 05).

Os projetos alicerçados nesses dispositivos digitais (ARANHA; XAVIEIR, 2015) inovam aspectos norteadores do jornalismo e insinuam novas modelagens no fluxo de informações: pautas com foco na cidadania, organização de redações virtuais, processos colaborativos de produção de conteúdo, objetividade da informação compreendida como categoria cognitiva, posicionamento crítico na cobertura, remodelagem do modelo anglo-saxão, experimentalismo formal - estilo, estrutura narrativa e sistema de codificação - e conceitual - pesquisas universitárias - e novas possibilidades de tipos de financiamento (SQUIRRA, 2012).

Os consumidores de conteúdos informativos podem se tornar produtores e o caminho contrário também é válido, porque a informação segue fluxos diversos e sofre modificações ao longo do percurso. Isso se justifica, segundo Jenkins (2009), sobretudo pela redefinição do papel e da posição do consumidor midiático:

Se os antigos consumidores eram tidos como passivos, os novos consumidores são ativos. Se os antigos consumidores eram previsíveis e ficavam onde mandavam que ficassem, os novos consumidores são migratórios, demonstrando uma declinante lealdade a redes ou a meios de comunicação. Se os antigos consumidores eram indivíduos isolados, os novos consumidores são mais conectados socialmente. Se o trabalho de consumidores de mídia já foi silencioso e invisível, os novos consumidores são agora barulhentos e públicos (JENKINS, 2009, p. 47).

Essa mudança na posição do consumidor midiático ocorre, principalmente, porque a internet permite a qualquer pessoa criar conteúdos e formatos. Esses conceitos de Jenkins podem ser comparados às indicações de Benkler (2006), para quem a internet representa uma mudança radical nas antigas tendências de comunicação, justamente porque é o primeiro meio de comunicação que consegue expandir o seu alcance ao descentralizar a estrutura de produção e de distribuição de informações, cultura e conhecimento. A maior parte das tecnologias que compõem a internet é baseada em recombinações e está aberta, ou seja, não está sob o controle de patentes ou outras formas que bloqueariam o acesso à rede, o que facilita o compartilhamento e a recombinação de conteúdos. 


\title{
míDiA

Silveira (2008), em uma interpretação similar à de Benkler, observa que há uma série de práticas socioculturais que reconfiguraram as redes informacionais, transformando-as em um espaço comum:

\begin{abstract}
Uma série de práticas socioculturais reconfiguraram as redes informacionais como um terreno comum - commons, no sentido anglo-saxônico - e incentivaram a produção de processos, repositórios e interfaces a partir do ciberespaço ou em seu redor, tais como a música tecno, a Wikipedia, as redes sociais, a blogosfera, o jornalismo open source, o desenvolvimento de softwares livres, [...] as licenças Creative Commons e até o YouTube (SILVEIRA, 2008, P. 86).
\end{abstract}

Em tese, o tipo de comunicação que prospera no ambiente digital está relacionado à livre expressão. "É a transmissão de fonte aberta, a livre divulgação, a transmissão descentralizada, a interação fortuita, a comunicação propositada e a criação compartilhada que encontram sua expressão na internet" (CASTELLS, 2003, p. 165). O ambiente digital permite, portanto, uma nova cultura: a cultura participativa. Os dispositivos das novas tecnologias de comunicação e informação, por sua interatividade e multifuncionalidade, são potenciais para fortalecer o processo democrático; proporcionam trocas de informações, consultas, debates, de maneira direta e rápida, livres de obstáculos burocráticos. Como aponta Correia (2008, p. 83-84),

\begin{abstract}
insiste-se num apelo a um novo paradigma que conduziria ao desenvolvimento de uma nova variedade de democracia, cujos traços seriam: a) interactividade - com todos os utilizadores comunicando uns com outros numa base de reciprocidade; b) globalidade - graças à ausência de fronteiras nacionais; c) liberdade de discurso e de associação; d) construção e disseminação de informação não submetida à censura oficial; e) consequente possibilidade de desafiar as perspectivas oficiais, as rotinas oficiais e instaladas.
\end{abstract}

$\mathrm{Na}$ tentativa de entender como as novas tecnologias possibilitam novos modelos de comunicação, sobretudo em âmbitos locais, optou-se por analisar, sob a ótica da Economia Criativa, as atividades de comunicação da Casa do Hip Hop Bauru, projeto gerenciado pelo Ponto de Cultura Acesso Hip Hop. A escolha da cidade, bem como desse Arranjo Produtivo Local (APL) justifica-se, como SANTOS e SILVEIRA (2001) apontam, pelo fato de Bauru fazer parte de uma região concentrada, ocupada por próteses tecnológicas digitais e analógicas, que criam uma ecologia criativa facilitadora de projetos inventivos no campo da cultura e comunicação. O município tem hardware 


\section{míDiA \\ eC \\ DiAno}

e software para a articulação de projetos do campo da economia criativa em seus principais componentes: patrimônio histórico, mídias, artes e inovações técnicas funcionais (PLANO DA SECRETARIA DA ECONOMIA CRIATIVA - 2011-2014) ${ }^{3}$.

\section{O Colaborativo online}

O jornalismo colaborativo é definido como jornalismo feito por mais de uma pessoa, pessoas que contribuíram para o resultado final do que é publicado. (FOSCHINI; TADDEI, 2006, p.19). Todas as pessoas, munidas de celular ou câmera, postando em um blog, seriam potencialmente repórteres. O jornalismo, como o conhecemos, estaria, dessa forma, se modificando (MORETZSOHN, 2006, p.63).

(...) a revolução digital trouxe, além da facilidade de distribuição da mensagem, a possibilidade de o receptor participar mais ativamente na (re)construção da mensagem, transformando os receptores em autores (CARNIELLO, 2003, p. 126).

A hipermídia, portanto, desenvolve um ambiente propício à colaboração participativa de conteúdos por usuários leigos, já que se tornou muito fácil o registro de informações e a captação de imagens, que pode ser feita com um simples celular. Enquanto o jornalismo tradicional de massa transmite informações padronizadas, as informações que trafegam pela internet são tão diversificadas quanto quem as produz e as consome, assegura-nos ALZAMORA (2006, p.11). Entretanto, existe a necessidade de se pensar como essa linguagem hipermidiática - híbrida, processual e interativa será apropriada de forma criativa pelo Jornalismo. Dessa maneira, ganha força a cultura interativa e participativa definida a partir do desejo do usuário de desempenhar um papel ativo na elaboração de informações, premissa essencial para a democratização da mesma, conforme MORETZSOHN (2007, p.17). Na web, é possível conceber uma comunicação mais complexa e dinâmica do que aquela produzida nas mídias que seguem exclusivamente o modelo broadcast. Configura-se, assim, uma nova forma de interação mútua, diferente e contrária à interação reativa, como aponta Primo:

(...) a interação mútua é aquela caracterizada por relações interdependentes e processos de negociação, em que cada interagente participa da construção

\footnotetext{
${ }^{3}$ http://www.cultura.gov.br/secretaria-da-economia-criativa-sec (Acesso 15/11/2013, às 10h08).
} 
inventiva e cooperada do relacionamento, afetando-se mutuamente; já a interação reativa é limitada por relações determinísticas de estímulo e resposta (PRIMO, 2007, p.57).

Com o avanço da tecnologia e o aumento de usuários da web, o número de fontes de notícias se multiplicou. A notícia, até então sob domínio de donos dos meios de comunicação, perdeu a exclusividade e se tornou uma ferramenta pública.

É nesse contexto que o jornalismo colaborativo na web se desenvolve. Os defensores dessa prática argumentam que a apuração coletiva gera uma mídia mais abrangente e multilateral A apuração dos acontecimentos é feita levando em consideração o princípio jornalístico de que nenhum fato acontece isoladamente e, sendo assim, pode ser visto de diversos ângulos. Nunca são apenas dois lados, ou versões, como defendem teorias anteriores.

\section{O Local e Cidadão como elementos do Jornalismo}

Apesar do cenário globalizado, Barbosa (2003) lembra que as informações de caráter local também sempre foram de grande relevância para o jornalismo. Entretanto, "o dado novo é que, no jornalismo digital, a estrutura das redes permite novas possibilidades para a geração dos conteúdos locais, ampliando o espaço para a sua veiculação" (BARBOSA, 2003, p. 1). Grier (2008) destaca o jornalismo cidadão como sendo aquele que incide sobre histórias locais em contraponto com eventos nacionais; podendo ser produzido tanto por organizações noticiosas estabelecidas quanto por meio daqueles que não estão inseridos, e nem sempre é 'notícia' no sentido tradicional.

\footnotetext{
Operações de mídia Hiperlocal são geograficamente baseadas, voltadas para a comunidade, organizações nativas e originais em reportar notícias para a web e pretendem preencher as lacunas percebidas na cobertura de uma questão ou região e promovem o engajamento cívico (METZGAR ET AL, 2010, p. 7).
}

Para López García (2008), a comunicação local interpreta a realidade pela ótica dos valores compartilhados e tem contribuído para a personificação de um cenário da comunicação atual, no qual a dupla e simultânea tendência do local e do global apresenta novos recursos, cujas referências dos comunicantes são extraídas das duas esferas, que são complementares durante as ações comunicativas. 
O jornalismo cidadão envolve uma proposta de produção de informação que contribua para que a/o cidadã/cidadão seja livre e independente, satisfatoriamente informado para que possa tomar decisões políticas que fortaleçam a democracia. Esse é um dos pressupostos do jornalismo ocidental, desde o advento da revolução francesa. Sua capacidade de articulação de narrativas sobre a atualidade, a validação de seus conteúdos e análises, a amplitude de suas observações, o foco crítico em setores significativos da realidade factual e a extensão de sua divulgação deram ao jornalismo, ao longo dos últimos duzentos anos, uma base de credibilidade e autoridade social (ARANHA, Â. S.; XAVIER, J. T.; 2015, p. 9).

No âmbito do jornalismo digital, o local pode ser compreendido a partir da sobrevivência dos antigos modelos, em sintonia com as apostas e recursos midiáticos dos novos tempos. Nesse ponto,

\begin{abstract}
a informação local do terceiro milênio tem que ser uma informação de qualidade, plural, participativa, imaginativa, que explique o que acontece no âmbito onde está sediado o veículo de comunicação, para quem informa e que narre o que afeta e interessa os habitantes desse território espacial, inclusive, quando se produz fora. A informação local do terceiro milênio deve promover a experimentação e converter os cenários de proximidade em lugares de comunicação eficiente e lugares de onde possam ser exportadas novas linguagens e formatos para a comunicação mundial (LÓPEZ GARCÍA, 2008, p. 34).
\end{abstract}

Lemos (2011, p.12) aponta o jornalismo digital localizado como uma conjunção de funções pós-massivas e massivas, onde o usuário pode ter informações mais precisas sobre o seu local de interesse a partir de um cruzamento de notícias.

A dimensão hiperlocal no jornalismo (já que ele é sempre local) refere-se,
em primeiro lugar, a informações que são oferecidas em função da
localização do usuário (sobre o bairro, a rua, etc), e em segundo lugar, pelas
características pós-massivas desse novo jornalismo onde qualquer um pode
ser produtor de informação. Essa é uma das tendências atuais do
jornalismo: vinculação de notícias cruzando diversas fontes, oficiais,
profissionais e cidadãs à geolocalização.

A partir desse entendimento, pode-se observar a aproximação das práticas do jornalismo hiperlocal com as do jornalismo cidadão, em especial no que se refere ao envolvimento das comunidades e suas organizações com relação aos problemas sociais, econômicos e ambientais urbanos que enfrentam e que, sistematicamente, não são noticiados ou são mal noticiados pelo jornalismo tradicional.

\title{
4. O Local como recriação do criativo
}




\section{míDiA

Os denominados territórios criativos são formados por organizações, instituições e espaços de produção de conhecimento cultural. Nesses espaços, são atores os homens na sua ontológica vocação para serem sujeitos em sua autorreflexão e na reflexão sobre seu espaço e seu tempo, são seres de relação (FREIRE, 1967 p.36-39). No espaço urbano, esses territórios são ocupados por ateliers criativos de produtos, processos e serviços de cultura, próteses tecnológicas digitais e analógicas. O geógrafo Milton Santos (2001) vê esse processo de ocupação territorial complexo e contraditório por criar a possibilidade de múltiplas leituras do real. Leituras como fábula, leituras como perversidade e leituras como possibilidades. Nos Círculos de Cultura esses conceitos são revisitados e ressignificados pelos sujeitos aprendentes (XAVIER, J. T. P.; XAVIER, P. A. M., 2015). O estágio da fábula se apresenta como a da visão de mundo que cada sujeito traz para o círculo de diálogo. No estágio da perversidade, as visões de mundo de cada sujeito são problematizadas no coletivo aprendente. No terceiro estágio, como fruto do diálogo e da confrontação de visões de mundo, se revelam como possibilidades as intervenções futuras dos sujeitos aprendentes desse coletivo, caracterizado como Círculo de Cultura.

De fato, se desejamos escapar à crença de que esse mundo assim apresentado é verdadeiro, e não queremos admitir a permanência de sua percepção enganosa, devemos considerar a existência de pelo menos três mundos num só. O primeiro seria o mundo tal como nos fazem vê-lo: a globalização como fábula; o segundo seria o mundo tal como ele é: a globalização como perversidade; e o terceiro, o mundo como ele pode ser: uma outra globalização (SANTOS, 2001, p. 18).

Conceitos fundamentais da reflexão de SANTOS (2001) podem ser eleitos como temas geradores, e reinventados pelos agentes, tais como "unicidade técnica", "convergência dos momentos", "motor único" e "cognoscibilidade do planeta".

Todavia, pode-se pensar na criação de um outro mundo, mediante uma globalização mais humanizada. As bases materiais do período atual são, entre outras, a unicidade da técnica, a convergência dos momentos e o conhecimento do planeta. É nessas bases técnicas que o grande capital se apoia para construir a globalização perversa citada acima. Mas, essas mesmas bases técnicas poderão servir a outros objetivos, se forem postas a serviço de outros fundamentos sociais e políticos. Parece que as condições históricas do fim do século XX apontavam para essa última possibilidade. Tais novas condições tanto se dão no plano empírico quanto no plano teórico (SANTOS, 2001, p.20). 
A unicidade técnica é a "malha de tecnologia" - analógica e digital - que se desenvolve em um determinado espaço territorial (XAVIER, J. T. P.; XAVIER, P. A. M., 2015), e essa "malha" forma uma ecologia digital que permite aos agentes a captação, edição e difusão de elementos culturais e simbólicos em ateliers criativos formados por coletivos de cultura. "As conexões desses ateliers criativos permitem a convergência de momentos virtuais - espaços digitais de trocas de informações com os momentos históricos e espaços reais de construção coletiva de conhecimentos" (XAVIER, J. T. P.; XAVIER, P. A. M., 2015, p.12). Essa articulação entre os dois momentos amplia os espaços aprendentes, com a apropriação dos diversos segmentos sociais das tecnologias digitais capilarizadas, o alargamento dos espaços de leitura, interpretação e intervenção, e a ampliação do diálogo entre os diversos agentes aprendentes.

Os investimentos concentrados em tecnologia formam as regiões concentradas (SANTOS, 2001), ocupadas por próteses digitais e analógicas, espaços propícios para a troca de informações de agentes inovadores e a construção coletiva, de forma vertical, mais aprofundada, e de forma horizontal; ampliada. No cenário constituído pelos Círculos de Cultura presencial e digital os sujeitos históricos aprendentes produzem novos conhecimentos de gestão de processos, de pessoas e recursos, gestão de valores materiais e imateriais, nos espaços de intersecção dos diversos territórios criativos de cultura.

\section{Ponto De Cultura Acesso Hip Hop}

Reconhecida como Ponto de Cultura pelo Governo Federal desde 2011, a ONG Ponto de Cultura Acesso Hip Hop tem o objetivo de promover a inclusão social por meio do hip hop. Isso ocorre em consequência de iniciativas que procuram dar a artistas locais oportunidades para que expressem sua criatividade. O Acesso Hip Hop consolidou-se na cidade como um ponto de conexão que se caracteriza como um círculo de cultura, nos seus aspectos fundamentais, com experiências presenciais e digitais. Esse ponto de conexão atua como protagonista na articulação dos arranjos produtivos locais de cultura (APLc) e das cadeias produtivas de produtos, serviços e processos criativos na cidade. Suas operações se estendem para arranjos culturais, em várias 


\section{míDiA \\ eC DiAno}

\section{PPGMC}

linguagens, das mais tradicionais às mais recentes. Como gestores de projetos culturais, os responsáveis por esse ponto de cultura contribuem para o fortalecimento do cenário independente - em diversas linguagens e plataformas culturais -, e para a formação de novos públicos, não apenas os tradicionais do mercado de cultura, aquele mercado coordenado pelos arranjos produtivos locais de cultura e bens simbólicos monopolistas e centralizadores da criação, seleção, edição e difusão de produtos, serviços e processos culturais hegemônicos.

Esse projeto contribui para a consolidação de uma leitura crítica sobre a gestão dos processos culturais locais, como se viu nos debates que aqueceram as discussões durante o processo de criação do Conselho Municipal de Cultura, em articulação com o poder público local e com organizações culturais da sociedade civil e de setores organizados focados na cultura. Esse debate estimulou a reflexão coletiva e trouxe à tona novos desafios, como o ingresso no Sistema Nacional de Cultura - SNC -, instrumento de política pública inclusiva do governo federal, que investe na pluralidade cultural, na formação de novos produtos e novos públicos alinhada à visão do Ministério da Cultura e da Secretaria Nacional de Economia Criativa. Uma das principais características dos projetos relaciona-se à formação de novos operadores, produtores culturais e fruidores, em todas as etapas do ciclo criativo: elaboração, planejamento, análises, proposição de planos, execução de funções e mecanismos de mensuração dos resultados. Cada etapa procura desenvolver ferramentas específicas baseadas no conceito de "tecnologias sociais", processos inovadores construídos de formas coletivas e colocados à disposição de atores sociais. Esse processo impulsiona a ampliação progressiva de protagonistas em redes horizontais, articuladas e capilarizadas em bairros centrais e periféricos, mais qualificados nos planos intelectuais, conceituais, técnicos e ético-estéticos. Tais protagonistas em rede ampliada qualificam seus processos de comunicação multilaterais: poder público, agentes elaboradores de políticas públicas, produtores culturais independentes e de mercado, organizações sociais e culturais, instituições de ensino e arranjos culturais institucionalizados. 


\section{míDiA

Diante das atividades realizadas e da intervenção na cidade, o ponto de Cultura Acesso Hip Hop "lê", interpreta e intervém no território criativo da cidade de Bauru. Suas ações propositivas imprimem "digitais" em todas as topografias da cidade, por meio de vários projetos culturais. Seus projetos estimulam inovações em gestões de processos, pessoas e recursos, características dos projetos em desenvolvimento no município, como o "Projeto Ensaio", o Projeto Rap Hour", o Combo 5 Elementos ${ }^{6}$ e o da Semana Municipal de Hip Hop. Já em sua quinta edição, em 2015, a Semana Municipal do Hip Hop se tornou por meio de mobilização social, há dois anos, uma política cultural da cidade após a aprovação da lei 6358/2013. Por determinação dessa lei, parte do orçamento municipal direcionado à cultura é destinado para a realização de um festival que, além de oferecer shows e oficinas para a população, também valoriza a diversidade cultural e o conhecimento sobre questões sociais, raciais e de gênero, discussões que também chegam às escolas e entidades públicas da cidade.

Em 2015, ocorreu a inauguração da "Casa do Hip Hop Bauru” com uma ocupação ativa da antiga Estação Ferroviária, localizada no centro antigo de Bauru em um prédio tombado como patrimônio histórico-cultural pela Prefeitura. A Casa também faz parte da Rede Nacional de Economia e Empreendimentos Solidários do Hip Hop, abriga coletivos independentes como a Frente Feminina de Hip Hop de Bauru ${ }^{7}$ e a Biblioteca Móvel - Quinto Elemento ${ }^{8}$, e oferece atividades diárias gratuitas, entre oficinas dos quatro elementos básicos da cultura, oficinas de dança, projetos musicais e audiovisuais, cine debate, além de cursinho pré-vestibular. A articulação em rede ampliada mobiliza e qualifica a utilização dos recursos presentes no município.

\footnotetext{
${ }^{4} \mathrm{O}$ projeto Ensaio é realizado mensalmente pelo Ponto de Cultura Acesso Hip Hop, em parceria com a Secretaria Municipal de Bauru. Cada mês, o evento acontece em um bairro periférico diferente, e visa a fomentar a cultura hip hop na cidade. A Semana Municipal do Hip Hop é realizada em espaços públicos, periféricos e centrais, em articulação com o poder público local, realizado em vários pontos da cidade.

${ }^{5}$ Lançado em 2013, o Rap Hour leva shows de rap de convidados de Bauru e região para o Teatro Municipal da cidade.

${ }^{6}$ Projeto que leva os quatro elementos do Hip Hop para as escolas públicas de Bauru e todo o interior de São Paulo.

${ }^{7}$ Desde 2012, as mulheres que compõem o movimento Hip Hop em Bauru têm se organizado em coletivo para realizar debates, oficinas, saraus e rodas de conversa com o objetivo de discutir o papel da mulher no movimento Hip Hop.

${ }^{8}$ A Biblioteca Móvel - Quinto Elemento existe desde 2014, com ações de distribuição e troca gratuita de livros no Calçadão de Bauru, uma das principais vias de comércio popular da cidade.
} 


\title{
míDiA eCOti DiAno
}

\section{Por um novo Jornalismo Cidadão e Colaborativo}

$\mathrm{Na}$ plataforma online (www.casahiphopbauru.com.br/), a Casa do Hip Hop Bauru produz e gera conteúdos relativos a assuntos de relevância para a cultura Hip Hop no cenário bauruense. Um dos principais focos de atuação desse site objetiva a divulgação e cobertura de eventos culturais independentes, que ocorrem sob a gerência do Ponto de Cultura Acesso Hip Hop. Ao darem visibilidade aos produtores culturais autorais da cidade nesse espaço de comunicação, os comunicadores procuram fomentar o cenário independente de Bauru, bem como destacar determinados aspectos sociais, econômicos e políticos da cidade.

Segundo Berger \& Luckmann (2004), um meio de comunicação com tais configurações promove uma renovação do espaço público com a inclusão pelo jornalismo de "instituições intermediárias", aquelas que reconhecem no cidadão o direito de participar da construção de sentido e, consequentemente, da construção social da realidade, o que reduz a crise subjetiva e intersubjetiva de sentido alimentada pela tendência à alienação e anomia que se verifica na modernidade (VIZEU; ROCHA; MESQUITA, 2010). Com isso, há um aumento considerável no potencial de engajamento cívico:

\begin{abstract}
A atividade online de pessoas interessadas em expor ideias, defender suas causas ou simplesmente opinar a respeito de fatos políticos do cotidiano mostra uma vitalidade inédita para o debate político. Mais do que partidos e governos, esse engajamento com questões políticas a partir do uso de mídias talvez seja um dos principais horizontes da democracia. [...] Política, neste sentido amplo, diz respeito às possibilidades de ação no espaço público, isto é, à possibilidade de ser quem se é, defender publicamente as ideias que se tem não só sobre governo e administração, mas também sobre modos de pensar e estilos de vida (SÁ MARTINO, 2014, p. 108-109).
\end{abstract}

O projeto de comunicação da Casa conta com quatro gestores fixos que dividem entre si funções essenciais para o funcionamento do site. A organização dos textos a serem publicados, a revisão, diagramação para a web e também o auxílio aos demais participantes em coberturas textuais cabe a uma representante da Casa do Hip Hop que acumula a função colaborativa de assessora da Casa do Hip Hop e do Ponto de Cultura. Há também a gestora de imagens/fotos, responsável pela organização das imagens a 


\section{míDiA \\ eC DiAno}

\section{PPGMC}

serem divulgadas no site (e em outras mídias digitais), pela instrução e auxílio aos demais participantes do projeto em coberturas fotográficas. O gestor de mídias sociais controla a divulgação do site na internet e é o responsável pela manutenção das páginas de mídias sociais, principalmente as contas no Facebook da Casa (fb.com/Casa-do-HipHop-Bauru-459089607594322) e do Ponto de Cultura (fb.com/Ponto-De-CulturaAcesso-Hip-Hop-169696546470431). Além de suas funções específicas, todos os gestores auxiliam na criação de pauta e no recrutamento de novos colaboradores, nas instruções à equipe existente e aos novos integrantes, nas reuniões com possíveis e atuais parceiros e também nas coberturas de eventos.

Apesar de funções definidas no modelo de comunicação, o diferencial adotado para a manutenção do site é a sua gestão de caráter colaborativo, aberto a todos os cidadãos bauruenses que queiram colaborar. Nesse aspecto, para Varella (2008), o jornalismo-cidadão diz respeito mais a um desejo coletivo de participação na produção de informação do que à ampliação de mecanismos de interação on-line. Não se trata, portanto, de um movimento derivado de um aumento da oferta de meios sociais on-line, distanciando-se de uma explicação mais tecnicista; ao contrário, a oferta dos meios que é condicionada, em termos, por uma demanda crescente de participação social na produção de mídia. Sendo assim, o jornalismo participativo, colaborativo ou cidadão é "uma ação por meio da informação", porque, segundo Varella (2007, p. 80), o cidadãorepórter informa algo porque quer que algo seja feito, "que seu bairro esteja limpo, que a prefeitura proporcione melhor atendimento, que o professor ensine com mais dedicação ou que a coleta de lixo seja mais organizada e eficiente". Essa visão localiza o "jornalismo-cidadão" como uma narrativa local.

No caso do projeto da Casa do Hip Hop de Bauru, apesar de ser um projeto aberto à livre colaboração, por natureza, a maioria dos colaboradores são estudantes universitários, com boa parte de graduandos dos cursos de Jornalismo da cidade. De acordo com os coordenadores do Ponto de Cultura, as pautas são encaminhadas para uma lista de emails e a produção de conteúdos se dá de acordo com o interesse, disponibilidade e acordo entre os colaboradores e os gestores do projeto. Todas as decisões são discutidas 


\section{míDiA

e tomadas em conjunto pelos colaboradores, sendo cada um deles também responsável pela sugestão e produção contínua de pautas, textos, fotos e materiais em diversos formatos. Por meio de oficinas e da prática do que se estuda, os colaboradores podem compreender o funcionamento do processo de cobertura colaborativa por meio da troca de tecnologias sociais e experiências envolvidas no processo, desde o planejamento da cobertura até a divulgação do produto final, sempre trabalhando nas plataformas digitais. Em cada cobertura, os colaboradores interessados realizam trabalhos de produção de textos (caracterizando a obra artística vista), entrevistas (colhendo impressões de públicos e artistas), fotografias (registrando os momentos e conceituando-os) e produções em vídeo (exercitando a linguagem audiovisual).

As experiências do trabalho colaborativo permitem trocas de conhecimentos entre os membros do grupo, resultando numa formação cidadã, consciente e atuante a partir da prática colaborativa e espontânea. Essa cobertura potencializa a expressão dos eventos, agrega valores às ações realizadas na cidade e estimula a criação de um acervo de registros da "cena atual" que seria, praticamente, ignorado pelo jornalismo convencional. E essa cobertura colaborativa democratiza a cultura ao viabilizar a veiculação de seus produtos, promover iniciativas culturais e cobrir jornalisticamente os acontecimentos em uma plataforma livre, a internet. Deve-se considerar, ainda, que o processo de registro de produções culturais decorrente da cobertura de eventos gera não só incentivo à produção artística local, como também a compilação e preservação da memória cultural. Contribui, portanto, para a criação de uma identidade artística e social para a cidade.

Como apontam Aranha e Xavier (2015, p.12), com as novas possibilidades oriundas de um modelo colaborativo e cidadão, o

\footnotetext{
"discurso único" e unidimensional passa a sofrer a concorrência das narrativas organizadas por esses novos Arranjos Produtivos Locais Intensos de Conteúdo Cultural (ApliCs). A fábula informativa agora disputa espaço com as narrativas das perversidades da exclusão na exclusão, e abre espaço para o discurso da possibilidade da mudança. "A tirania da informação e do dinheiro" - que caracteriza o sistema ideológico - é desnudada pelos conteúdos críticos que articulam uma esfera pública radical, precária, alternativa. As trocas de informações e conteúdos nessa esfera pública radical ampliam as percepções da realidade. Aumenta a cognoscibilidade do planeta,
} 
que passa a ser escrutinado de forma intensa e extensa em seus estudos sobre o processo da globalização, assim como a necessidade de superação do pensamento único pela consciência universal.

\section{Considerações Finais}

As mudanças tecnológicas estabelecidas no final do século $\mathrm{XX}$ mudaram o ecossistema dos meios de comunicação e tocam, neste início do século XXI, todos os domínios da vida humana. Com o jornalismo, em específico, não foi diferente. A alteração do papel do jornalista, o uso massivo de redes sociais e o crescimento de coberturas colaborativas questionam o modelo industrial de jornalismo que se consolidou no século passado. Além da mudança no processo, as empresas jornalísticas passaram a sofrer para se manterem sustentáveis financeiramente. A valorização da cobertura de âmbito local pode oferecer alguma esperança nesse momento de incerteza do jornalismo. Embora algumas dúvidas se mostrem, o enfoque no local cidadão pode proporcionar um maior envolvimento da audiência. Juntamente com a criatividade, a prática jornalística calcada na localidade pode trazer grandes ganhos ao jornalismo atual. Resta tirar proveito disso e equacionar questões como fidelização, ampliação da audiência e financiamento, para que a inovação propiciada pela criatividade e pela tecnologia possa trazer desenvolvimento econômico e social, não só para o jornalismo.

Diante desse exposto, pode-se inferir que o jornalismo hiperlocal prevê iniciativas que contemplam uma mesma finalidade no contexto atual: apresentar a realidade sobre outros pontos de vista, apresentar uma nova visão de mundo e acreditar na pluralidade de informações para formar opiniões dos leitores e internautas. Aliado aos movimentos populares e movimentos sociais, bem como a todos os arranjos produtivos locais de cultura (APLc) e cadeias produtivas de produtos, serviços e processos criativos na cidade, esse pretende construir uma rede de conteúdo contrahegemônica, que dê as notícias e divulguem as reportagens que não são dadas e divulgadas em todos os outros lugares.

Afirma-se que a forma de controle das mídias pela sociedade tenha vindo à tona com a ferramenta da internet: novas fontes de informação com canais cada vez mais acessíveis, portais de notícias, redes sociais, postagens de acontecimentos em tempo 


\section{míDiA \\ eCOti \\ DiAno}

real, coberturas em vídeo, etc. São milhões de dados a serem comprovados, refutados e discutidos por cada usuário, cada internauta que tenha em suas mãos um dispositivo que pode lhe mostrar verdades não disponíveis nos até então únicos meios confiáveis de informação, os tradicionais meios de comunicação de massa brasileiros. Ademais, o jornalismo local praticado nos ambientes digitais fornece um importante referencial de sustentação das identidades culturais locais e pode colaborar com a participação cidadã mais qualificada e envolvida com os temas inerentes a cada local, principalmente aqueles em que as mídias tradicionais e hegemônicas costumam excluir da cobertura praticada atualmente, como é o caso operado pela Casa do Hip Hop de Bauru.

\section{REFERÊNCIAS}

ALZAMORA, Geane. Para além do jornalismo de massa: a diversidade da informação cultural na internet. In: PINTO, Júlio; SERELLE, Márcio. Interações Midiáticas. Belo Horizonte: Autêntica, 2006, pp. 153 -168.

ARANHA, A. S.; X, J. T. P.. Jornalismo cidadão e o protagonismo político local: as experiências do jornal "Voz do Nicéia" e do "Portal Participi". ÂNCORA-Revista Latinoamericana de Jornalismo, v. 2, n. 2, 2015.

BARBOSA, S. Jornalismo digital e a informação de proximidade: o caso dos portais regionais, com estudo sobre o UAI e o iBahia. Dissertação de Mestrado apresentada ao Programa de Pós-Graduação em Comunicação e Cultura Contemporâneas, na UFBA, Salvador (BA), Novembro de 2002. Disponível em: http://www.bocc.ubi.pt/pag/barbosa-suzana-portaismestrado.pdf. Acesso em: 31 jun. 2015.

BERGER, Peter L.; LUCKMAN, Thomas. A construção social da realidade. Lisboa: Dinalivro, 2004.

CARNIELLO, Mônica Franchi. Interatividade na publicidade digital. Revista ciências humanas, Taubaté , v. 9, n. 2, p. 125-128, 2003.

CARVALHO, J Maurício.; CARVALHO; A.M.G. Do hiperlocal aos insumos criativos: as mutações do jornalismo na contemporaneidade. In: CARVALHO,J.M; BRONOSKY (Org.) Jornalismo e Convergência. São Paulo, Cultura Acadêmica. 2014. p. 69-87

CASTELLS, M. Fluxos, Redes e Identidades: Uma Teoria Crítica da Sociedade Informacional. In: Castells, M. (Org). Novas perspectivas críticas em educação. Porto Alegre: Artes Médicas, 1996. 


\section{míDiA \\ ecoti \\ DiAno}

. A sociedade em rede. v. 1. São Paulo: Paz e Terra, 1999.

CHOI, Y. J. Local news. In W. Donsbach (Ed.), The international encyclopedia of communication: Blackwell Publishing. 2008

FOSCHINI, Ana Carmen \& TADDEI, Roberto Romano. Jornalismo Cidadão -Você faz a notícia. Coleção Conquiste a Rede. Overmundo. Disponível em: http://www.overmundo.com.br /banco/conquiste-a-rede-jornalismo-cidadao-voce-faz-a-noticia. Acesso em: 26/04/2016

FREIRE, P. Educação como prática da liberdade. Rio de Janeiro: Ed. Paz e Terra, 1967.

JENKINS, H. Cultura da convergência. São Paulo: Aleph, 2009.

LEMOS, A. Nova Esfera Conversacional. In: Dimas A Künsch, D.A, da Silveira, S.A, et al. Esfera Pública, redes e jornalismo. Rio de Janeiro. Editora. E-papers, 2009.

LÓPEZ GARCÍA, Xosé. Ciberperiodismo em la proximidade. Sevilla: Comunicación Social ediciones y publicaciones, 2008.

PERUZZO, C. M. K. Mídia Local, uma mídia de proximidade. Comunicação: Veredas, Ano $2 \quad-\quad n^{\circ} \quad 02 \quad-\quad$ novembro $2003 . \quad$ Disponível em: http://revcom.portcom.intercom.org.br/index.php/comunicacaoveredas/article/viewFile/5105/47 23. Acesso em: 28.07.2013.

Mídia Local e suas interfaces com a mídia comunitária no Brasil. Trabalho apresentado no Núcleo de Comunicação para a Cidadania, XXVI Congresso Anual em Ciência da Comunicação, Belo Horizonte/MG, 02 a 06 de setembro de 2003. Acesso no dia 28.07.2014, em:

http://www.portcom.intercom.org.br/pdfs/99061099541813324499037281994858501101.pdf.

METZGAR, Emily; KURPIUS, David; ROWLEY, Karen. Defining Hyperlocal Media: Proposing a Framework for Discussion. Annual meeting of the International Communication Association, Suntec Singapore International Convention \& Exhibition Centre, Suntec City,

Singapore, Jun 22, $2010 \quad$ Disponível em: <http://citation.allacademic.com/meta/p_mla_apa_research_citation/4/0/4/9/9/p404999_index.ht ml>. Acessado em: 23 fev. 2016.

MORETZSOHN, Sylvia. O mito libertário do "jornalismo cidadão". In Comunicação e Sociedade, volume 9-10, p 63-81, 2006.

, Sylvia. Pensando contra os fatos. Jornalismo e cotidiano: do senso comum ao senso crítico. Rio de Janeiro: Revan, 2007.

PERUZZO, C. M. K.; VOLPATO, M. O. Conceitos de comunidade, local e região: interrelações e diferenças. Artigo apresentado II Colóquio Binacional Brasil-México de Ciências da Comunicação, em abril de $2009 . \quad$ Disponível em: 
http://www.espm.br/ConhecaAESPM/Mestrado/Documents/COLOQUIO\%20BXM/S1/ cecilia\%20krohling\%20e\%20marcelo\%20volpato.pdf. Acesso em 15 fev. 2016.

PRIMO, Alex. Interação mediada por computador:comunicação, cibercultura, cognição. Porto Alegre: $2^{\circ}$ Edição, Sulina, 2008. (Coleção: Cibercultura)

SANTOS, M. Por uma outra globalização: do pensamento único à consciência universal. 5. ed. Rio de Janeiro: Ed. Record, 2001.

SANTOS, M.; SILVEIRA, M. L. O Brasil: território e sociedade no inicio do século XXI. Rio de Janeiro: Ed. Record, 2001.

SILVEIRA, S. A. Cibercultura, commons e feudalismo informacional. Revista FAMECOS, Porto Alegre, n 37, dez. 2008.

SQUIRRA, Sebastião (Org.). Ciber Mídias: extensões comunicativas, expansões humanas. Porto Alegre: Buqui, 2012.

XAVIER, J. T. P.; XAVIER, P. A. M.. Ler, Interpretar e Agir: um Círculo de Cultura Fora do Eixo. Razón y Palabra, v. 19, n. 89, 2015. 